\title{
The Association between Social Support and Happiness among Elderly in Iran
}

\author{
Babak Moeini', Majid Barati ${ }^{2}$, Maryam Farhadian ${ }^{3}$, Milad Heydari Ara ${ }^{4, *}$ \\ 'Department of Public Health, Social Determinants of Health Research Centre, School of Public Health, Hamadan University of Medical Sciences, \\ Hamadan, Iran \\ ${ }^{2}$ Department of Public Health, Research Center for Behavioral Disorders and Substance Use, Hamadan University of Medical Sciences, Hamadan, Iran \\ ${ }^{3}$ Department of Biostatistics, School of Public Health and Research Center for Health Sciences, Hamadan University of Medical Sciences, Hamadan, \\ Iran \\ ${ }^{4}$ Department of Public Health, Hamadan University of Medical Sciences, Hamadan, Iran
}

Background: Elderly people's life is affected by multiple factors including social support, which is of the utmost importance. This study aimed to explore the association between social support and happiness as well as the impact of types of social support on happiness among elders.

Methods: This descriptive and analytical study was carried out on 411 elderly men and women referred to the retirement, cultural, and rehabilitation centers in Hamadan, west of Iran. Participants were selected by a multi-stage random sampling method. The research instrument included a questionnaire consisting of three parts: demographic information, the Oxford Argyle Happiness Inventory, and a Questionnaire derived from Social Support Theory. The questionnaire was completed through a self-report study. The collected data were analyzed using Pearson correlation coefficients, multiple linear regression, independent t-tests, and one-way analysis of variance in IBM SPSS Software ver. 22.0 (IBM Corp., Armonk, NY, USA).

Results: The mean for happiness was reported as $41.17 \pm 15.2$. The values given for social support were $29.40 \pm 11.95$ and for its dimensions were $7.53 \pm 3.89$ and $13.70 \pm 4.90$ for informational support and emotional support, respectively. Moreover, the mean value for appraisal support was $3.48 \pm 2.37$ and was $4.70 \pm 2.56$ for instrumental support. Multiple linear regression analysis revealed that social support and demographic variables could account for approximately $25 \%\left(\mathrm{R}^{2}=0.25\right)$ of changes in the variable of happiness.

Conclusion: High social support could increase happiness among elders. The quality and quantity of social support can be taken into account as proper determinants and predictors of happiness among elders.

Keywords: Social Support; Happiness; Aged; Retirement

Received: October 19, 2017, Revised: February 4, 2018, Accepted: February 5, 2018

${ }^{*}$ Corresponding Author: Milad Heydari Ara https://orcid.org/0000-0001-9061-2614

Tel: +98-9386165242, Fax: +98-8138380509,E-mail: dm.heydariara@yahoo.com 


\section{INTRODUCTION}

Happiness is considered a positive inner experience originating from individuals' cognitive and emotional interpretation of their lives. ${ }^{1)}$ As indicated in this definition, happiness is also an all-encompassing concept underlain by two components, namely, emotion and cognition. The emotional component refers to pleasure (balance between pleasant and unpleasant affect), and the cognitive component pertains to mental health. ${ }^{2)}$ Considering outcomes related to happiness, a number of studies have suggested that a sense of happiness can be used as a basis for treating mental disorders, increasing hope, developing psychological resistance, and reinforcing defensive power against stress. ${ }^{3)}$ The effectiveness of using happiness as a pathway to treatment is supported by publications such as the World Health Organization's World Happiness Report, which ranked Iran as the 107th happiest nation among 155 countries in 2017. The country exhibits a higher happiness rate than Iraq and Afghanistan and a lower happiness rate than its other neighbors, such as Turkey, Pakistan, Azerbaijan, and Arab countries. $^{4}$

Similar to happiness, old age is experienced as one of the inevitable events in human life by a considerable proportion of the population in different communities. ${ }^{5)}$ Old age comes with the debilitation of physical and spiritual strength, thereby placing the elderly in a highly vulnerable position. The elderly can also suffer from problems such as loneliness, depression, anxiety, and, eventually, physical and mental disorders because of the "automated" life currently characterizing the modern world, residence in apartments or small homes, reduced number of children, children's immigration to other cities, and the consequent distance of any of them from their parents. ${ }^{6}$ These issues highlight the need to pay attention to the elderly age group, provide them with necessary support, and investigate and evaluate their needs in all of life's dimensions. One such dimension is social support received from family or friends. ${ }^{7}$ Research has demonstrated that factors such as levels of interaction and social support can affect the satisfaction and general health of elderly people. ${ }^{8)}$ Social support refers to assistance or support provided by members of social networks to an individual. ${ }^{9)}$ Rathus ${ }^{10)}$ believed that social support can adjust and diminish the unfavorable effects of mental pressure. The author also described different types of support: (1) emotional support, which involves listening to individuals' difficulties and showing empathy, care, understanding, and reassurance; (2) instrumental support, which pertains to provision of tangible assistance that a person needs; (3) informational support, which is the delivery of guidance and advice to increase the coping skills of individuals; and (4) appraisal support, which refers to the provision of feedback by others concerning quality of functioning and thus leading to corrected functioning. ${ }^{10)}$ Janevic et al. ${ }^{11)}$ in 2004 concluded that informational support, emotional support, mutual positive social action, tangible support, the number of close friends and relatives, and marital status are significantly correlated with the health status of elderly women. Investigations have also showed a significant and positive relationship between social support and happiness. ${ }^{11)}$ Countries provide different types of support to their elderly populations. In Iran, for example, the Ministry of Health and the Welfare Organization and Relief Committee provide elderly counseling services and food basket donations, implement the house caretaker and Shahid Rajaee plans, and exempt elderly caregivers from tax and insurance payments. ${ }^{12)}$ Despite these initiatives, Iran is confronted with a lack of studies devoted to the circumstances and living conditions of the elderly. Such explorations are important given the increasing population of elderly individuals and the necessity of understanding the factors that affect old people's quality of life. Accordingly, the present research was conducted to examine the effectiveness of social support for the elderly of Iran and determine the magnitude and importance of each social support structure on the elderly. The findings can serve as a reference in formulating strategies for care planning and intervention at the individual and group levels. It is hoped that these strategies will improve the quality of life and health of the elderly.

\section{METHODS}

\section{Design and Participants}

This cross-sectional study was conducted in 2016 in Hamadan City, western Iran. A total of 411 elderly people aged 60-75 years and receiving services from retirement, cultural, and rehabilitation centers (15 centers) were selected through multi-stage random sampling. First, all actively operating centers in Hamadan, including those that provide career support, cultural and sport services, and rehabilitation for the elderly, were visited. None of the centers are residential and are accessible only through medical rehabilitation centers. Second, the total elderly population of each center was determined, after which the number of individuals targeted for participation in the study was calculated based on the ratio of the total population in each center to the total population in all the centers in Hamadan. Third, the attendance schedules of the elderly in the centers were determined so that they could be invited to participate in the research (The elderly are randomly referred to centers for rehabilitation two days a week, with morning and afternoon sessions). Upon entry into a center, a potential participant was selected based on inclusion criteria and self-report questionnaires. The inclusion criteria were being a member of the centers, having an age of 60-75 years, and willingness to participate in the study (This age range was chosen given the mental issues included in the questionnaire and the inability of elderly individuals over 75 years to respond to such questions for different reasons). The exclusion criteria were reluctance to participate in the study, a history of mental disorders (Alzheimer's disease and dementia), and physical problems (visual and auditory problems). An elderly individual with hearing and vision impairments was excluded if the disorders exerted disruptive effects. Given that sample size can also be estimated with reference to level of happiness among the elderly, ${ }^{13)} \mathrm{a} P=0.5$ for level of happiness and a corresponding confidence level of $95 \%$ were considered in the estimation, which indicated that the sample size required for this study was 384 people. With consideration for an effect size of 
1.1, this size was expanded to 420 individuals. Out of 420 participants, $411(97.8 \%)$ expressed a willingness to voluntarily participate in the research.

This study was conducted following the approval of the Research and Ethics Committee of Hamadan University of Medical Scienes (approval no., IR.UMSHA.REC.1394.478) and in accordance with the ethical norms and standards stipulated in the Declaration of Helsinki.

\section{Measures}

For data collection, a questionnaire consisting of three sections was administered to the participants. The first section was the "demographic and background variables section," which contained questions about demographic characteristics (age, gender, marital status, occupation, literacy level, income, family dimension). The second section consisted of the standardized 29-item "Oxford Happiness Questionnaire," whose reliability and validity have been confirmed in different studies. ${ }^{14)}$ The items in this section were rated on a four-point Likert scale ranging from 0 ("totally unhappy") to 3 ("totally happy"). The minimum score (0) represents a low level of happiness, and the maximum score (87) indicates a high level of happiness. The normal scores obtained in the questionnaire fall between 40 and 42 . The third section comprised the "Social Support Questionnaire," which was adapted for the circumstances of this work. The original instrument required a review in terms of its structure and effectiveness in measuring social support in relation to happiness and was adapted by modeling similar questionnaires in other studies. ${ }^{15)}$ The adapted questionnaire consists of 10 items on emotional support, eight items on informational support, five items associated with instrumental support, and three items dealing with appraisal support. The respondents were asked to indicate their agreement or disagreement on a 3-point Likert scale that encompasses the options "never" ( 0 point), "sometimes" (1 point), and "always" ( 2 points). The lowest score in the test is 0 , and the highest is 52. A high score obtained by the respondents on this scale indicates that they receive desirable support. To measure the reliability of the Social Support Questionnaire, a pilot study was conducted on 30 elderly people from the given population. A Cronbach's alpha of $90 \%$ was obtained. To determine the content validity of the adapted instrument, it was submitted to 10 health education and promotion specialists for review. Finally, a content validity ratio of $78 \%$ and a content validity index of $76 \%$ were obtained.

\section{Data Analyses}

Analyses were performed using IBM SPSS ver. 22.0 (IBM Corp., Armonk, NY, USA). To determine the relationship among the study variables, Pearson's correlation analysis, multiple linear regression, independent t-tests, and one-way analysis of variance were carried out. A P-value less than 0.05 was considered significant in all tests.

\section{RESULTS}

Of the 411 participants, $74 \%$ were men and $88.3 \%$ were married (Table 1). The mean age of the respondents was 64.89 years (standard deviation [SD], 4.59). The other demographic characteristics of the participants are presented in Table 1.

As shown in Table 2, the mean score for happiness among the respondents was 41.17 . Out of the respondents, $47.32 \%$ reported being

Table 1. Frequency of demographic variables among participants

\begin{tabular}{|c|c|}
\hline Variable & No. (\%) \\
\hline \multicolumn{2}{|l|}{ Gender } \\
\hline Male & $304(74.0)$ \\
\hline Female & $107(26.0)$ \\
\hline \multicolumn{2}{|l|}{ Age (y) } \\
\hline $60-65$ & $263(64.0)$ \\
\hline $66-70$ & 83 (20.2) \\
\hline $71-75$ & $65(15.8)$ \\
\hline \multicolumn{2}{|l|}{ Marital status } \\
\hline Single & $48(11.7)$ \\
\hline Married & 363 (88.3) \\
\hline \multicolumn{2}{|l|}{ Literacy level } \\
\hline Below diploma & $152(37.0)$ \\
\hline Diploma & 104 (25.3) \\
\hline Academic & 155 (37.7) \\
\hline \multicolumn{2}{|l|}{ Occupation } \\
\hline Retired & $381(92.7)$ \\
\hline Other & $30(7.3)$ \\
\hline \multicolumn{2}{|l|}{ Family dimension } \\
\hline$<3$ & $248(60.3)$ \\
\hline$\geq 3$ & $163(39.7)$ \\
\hline \multicolumn{2}{|l|}{ Income (US\$) } \\
\hline$<300$ & $132(32.1)$ \\
\hline $300-500$ & $191(46.5)$ \\
\hline$>500$ & 88 (21.4) \\
\hline
\end{tabular}

Values are presented as number (\%).

Table 2. The correlation coefficients for happiness and social support variables

\begin{tabular}{|c|c|c|c|c|c|c|c|c|}
\hline Variable & 1 & 2 & 3 & 4 & 5 & 6 & $\begin{array}{c}\text { Mean } \pm \text { standard } \\
\text { deviation }\end{array}$ & $\begin{array}{c}\text { Range of } \\
\text { scores }\end{array}$ \\
\hline 1. Happiness & 1 & & & & & & $41.17 \pm 15.2$ & $0-87$ \\
\hline 2. Social support (total) & $0.454^{\star *}$ & 1 & & & & & $29.40 \pm 11.95$ & $0-52$ \\
\hline 3. Emotional support & $0.415^{\star \star}$ & $0.907^{\star *}$ & 1 & & & & $13.70 \pm 4.90$ & $0-20$ \\
\hline 4. Information support & $0.427^{\star \star}$ & $0.909^{\star *}$ & $0.758^{\star *}$ & 1 & & & $7.53 \pm 3.89$ & $0-14$ \\
\hline 5. Instrumental support & $0.352^{\star \star}$ & $0.823^{\star *}$ & $0.636^{\star \star}$ & $0.669^{\star \star}$ & 1 & & $4.70 \pm 2.56$ & $0-10$ \\
\hline 6. Appraisal support & $0.354^{\star \star}$ & $0.787^{\star \star}$ & $0.573^{\star \star}$ & $0.655^{\star \star}$ & $0.658^{\star \star}$ & 1 & $3.48 \pm 2.37$ & $0-8$ \\
\hline
\end{tabular}

${ }^{* \star}$ Correlation is significant at the 0.01 level. 
happy. The correlation between the different types of social support and happiness showed a significant relationship among all the study variables at a significance level of $0.01(\mathrm{P}=0.000)$.

Table 3 indicated that happiness was significantly and positively correlated with age $(\mathrm{P}=0.002)$, education $(\mathrm{P}=0.001)$, and income $(\mathrm{P}=0.001)$. The social support score in relation to these variables was 29.40. None of the demographic variables, except for marital status $(\mathrm{P}=0.005)$ and age $(\mathrm{P}=0.005)$, showed a significant relationship with social support. An increase in age could reduce the level of social sup-

Table 3. Associations between happiness and social support and demographic variables among participants

\begin{tabular}{|c|c|c|c|c|}
\hline \multirow{2}{*}{ Variable } & \multicolumn{2}{|c|}{ Total happiness } & \multicolumn{2}{|c|}{ Social support } \\
\hline & Mean $\pm S D$ & P-value & Mean $\pm S D$ & P-value \\
\hline Gender & & 0.124 & & 0.681 \\
\hline Male & $41.34 \pm 15.62$ & & $29.55 \pm 11.87$ & \\
\hline Female & $40.59 \pm 14.28$ & & $28.99 \pm 12.24$ & \\
\hline Age (y) & & 0.002 & & 0.050 \\
\hline $60-65$ & $42.53 \pm 15.28$ & & $30.11 \pm 12.02$ & \\
\hline $66-70$ & $41.45 \pm 13.84$ & & $29.75 \pm 11.60$ & \\
\hline $71-75$ & $35.14 \pm 15.74$ & & $26.10 \pm 11.77$ & \\
\hline Marital status & & 0.178 & & 0.005 \\
\hline Single & $37.19 \pm 14.24$ & & $24.89 \pm 12.28$ & \\
\hline Married & $41.67 \pm 15.34$ & & $30 \pm 11.80$ & \\
\hline Literacy level & & 0.001 & & 0.160 \\
\hline Below diploma & $37.34 \pm 15.35$ & & $28.13 \pm 12.25$ & \\
\hline Diploma & $44.86 \pm 14.15$ & & $31.03 \pm 11.80$ & \\
\hline Academic & $42.39 \pm 15.19$ & & $29.55 \pm 11.70$ & \\
\hline Occupation & & 0.057 & & 0.877 \\
\hline Retired & $41.20 \pm 15.50$ & & $29.38 \pm 12.04$ & \\
\hline Other & $40.40 \pm 12.16$ & & $29.73 \pm 11$ & \\
\hline Family dimension & & 0.373 & & 0.353 \\
\hline$<3$ & $40.60 \pm 15.38$ & & $29.85 \pm 12.03$ & \\
\hline$\geq 3$ & $41.97 \pm 15.19$ & & $28.73 \pm 11.85$ & \\
\hline Income (US\$) & & 0.001 & & 0.207 \\
\hline$<300$ & $37.76 \pm 14.92$ & & $28.68 \pm 11.74$ & \\
\hline $300-500$ & $41.46 \pm 15.11$ & & $28.98 \pm 12.26$ & \\
\hline$\geq 500$ & $45.55 \pm 15.09$ & & $31.93 \pm 11.51$ & \\
\hline
\end{tabular}

SD, standard deviation. port received by the elderly.

Table 4 presents the results of the multiple linear regression conducted on happiness, social support, and the demographic variables. The beta coefficient indicated that informational support was highly correlated with happiness. The $\mathrm{R}^{2}$ of the test was 0.255 , indicating that $25 \%$ of the variance in happiness could be explained by social support and the demographic variables. The results of this study suggest that there is a significant relationship between happiness and two components of social support such as information and emotional support, even when controlling for confounding variables such as age, gender, and so on.

\section{DISCUSSION}

The purpose of this study was to investigate the relationship between social support and happiness among elderly people. Individuals endowed with favorable social support were expected to exhibit a more positive view toward life, a higher level of satisfaction, and better functioning than those who do not receive such support. ${ }^{16)}$ The results suggested a significant and positive relationship between the dimensions of social support (informational, appraisal, etc.) and happiness; that is, individuals receiving more social support had higher levels of happiness. The findings are consistent with those of similar studies. ${ }^{17)}$ The types of support that can be provided to the elderly include trust; emotional, informational, instrumental, appraisal, psychological, and financial support; the presence of kinship networks; a sense of belonging and affiliation; and understanding, sympathy, and friendship. Having positive effects on human life and consequently on human happiness, social support not only promotes health but also diminishes medical problems such as depression and anxiety. ${ }^{18)}$ Social support can drive improved health status provided that it establishes a sense of intimacy. ${ }^{19)}$ The protective effects of social support can result from several processes, such as positive access to information about health and healthcare services, encouragement of healthy behaviors, assistance in the use of healthcare services, and the provision of tangible assistance. ${ }^{17)}$ Living with family members, including spouses and children,

Table 4. Multiple linear regression for associations between happiness and social support and demographic variables among participants

\begin{tabular}{|c|c|c|c|c|c|}
\hline \multirow{2}{*}{ Variable } & \multicolumn{5}{|c|}{ Happiness } \\
\hline & B & Standard error & Beta (standardized coefficients) & P-value & t-value \\
\hline 1. Emotional support & 0.669 & 0.217 & 0.215 & 0.002 & 3.08 \\
\hline 2. Information support & 0.774 & 0.297 & 0.197 & 0.009 & 2.61 \\
\hline 3. Instrumental support & 0.233 & 0.392 & 0.039 & 0.552 & 0.596 \\
\hline 4. Appraisal support & 0.212 & 0.409 & 0.033 & 0.605 & 0.518 \\
\hline 5. Age & -0.297 & 0.153 & -0.089 & 0.053 & -1.93 \\
\hline 6. Gender (reference category: male) & -0.034 & 1.91 & -0.001 & 0.986 & -0.018 \\
\hline 7. Marital status (reference category: single) & 0.542 & 2.55 & 0.011 & 0.832 & 0.212 \\
\hline 8. Literacy level (reference category: below diploma) & 8.80 & 2.60 & 0.157 & 0.001 & 3.38 \\
\hline 9. Occupation (reference category: other) & -1.08 & 2.73 & -0.018 & 0.692 & -0.396 \\
\hline 10. Family dimension (reference category: $\leq 3$ ) & 1.80 & 1.39 & 0.058 & 0.195 & 1.29 \\
\hline 11. Income & 8.93 & 0 & 0.049 & 0.279 & 1.08 \\
\hline
\end{tabular}

Variable no. $1,2,3,4,5$, and 10 are considered quantitatively. $R^{2}=0.255$. 
and acquiring financial and emotional attention and support, create feelings of love, care, self-esteem, and value among the elderly, thus leading to a happy and healthy life. The results revealed that the sample receive above-average social support, consistent with the findings of Bozo. ${ }^{20)}$

The findings of the current work also suggested a significant relationship between social support and marital status and age. Marriage can create a sense of affection, love, and sympathy, which count as forms of social support that foster satisfaction and tranquility. Such feelings are absent or at low levels among unmarried individuals. The advantages of marriage as well as the density and quality of social support can likewise vary depending on culture. These results are in line with the findings of Heiydari et al. ${ }^{21)}$ Given the inverse relationship between age and social support, the results indicated that increased age could reduce the number of social networks and, subsequently, the level of subordinate social support among the elderly population. ${ }^{22)}$ This issue, along with the empty nest syndrome, the social characterization and context of today's society, children's concerns, and lack of opportunities to meet the needs of the elderly, can be another reason for the decline in social support with age. Gender was not significantly correlated with social support. The lack of difference in social support provided by family and friends to elderly men and women is attributed to Iranian and Islamic culture, in which respect for the elderly, especially parents, is of utmost importance. Thus, both male and female elderly individuals are revered by family and friends. The results showed no significant relationship between social support and education. The same was also true for income, family, and occupation. Given these results, individual differences in occupation, level of education, and income were disregarded as determinants of the level of social support provided to the elderly. Thus, these need not be emphasized in planning and policy making. In justifying the family dimension as a social network, it was concluded that the number of family members was not relevant merely because of the significance of communication skills and quality and social support.

In the current research, social support and its dimensions could predict happiness. The results are consistent with the findings of studies that confirmed the predictive power of social support for happiness. ${ }^{23)}$ In explaining these findings, it was assumed that relatives and strangers can act differently as they interact with elderly people; although family members always function as a source of emotional and instrumental support (e.g., money, gifts, and services), friends are unable to provide the same type of support. ${ }^{24)}$ However, informational and appraisal support can arise from both family members and friends. ${ }^{25}$ The friends of elderly individuals can accompany them in social activities more frequently than can their children or other relatives. Considering the power of social support to predict happiness, social support could increase self-confidence, self-disclosure, and selfesteem in an individual, thereby helping him/her achieve goals, satisfaction with life, and, consequently, happiness.

Note that there are three social support aspects that affect a person's health status and level of happiness. The first is associated with the features of social networks to which a person belongs, in which a link with a network is established through integrated relationships. This structural dimension encompasses the bases of individuals' relationships, the size of relationship networks, intimate friends available, and frequency of contact. The second aspect of social support is the content of social relationships, which is associated with the functions of social support that involve the features of emotional support, such as love and empathy. In this respect, participatory and advisory support is associated with thinking and feelings, informational support focuses on problem solving and data collection, and instrumental support refers to assistance and services. The third aspect of social support is social network evaluation, which involves the measurement of the quantity and quality of support as well as satisfaction with social relationships. ${ }^{26)}$ Promoting such support can play a significant role in increasing individuals' levels of happiness and satisfaction.

Similar to any other study, the present research has certain limitations, namely, the establishment of relationships with the elderly people, the acquisition of access to these individuals, and the lack of cooperation by some of them. The results of various studies have revealed that emotional support can exert the strongest impact on quality of life and happiness among the elderly. An equally important consideration, however, is that the elderly are also in dire need of services, financial assistance, and advisory support given their social, economic, and physical status. The findings highlight the need for increased social support to elderly people as this can elevate the levels of happiness in this age group. The amount and quality of support provided to elderly people by family and friends can serve as a predictor of level of happiness. Thus, society should provide the maximum social support (emotional, instrumental, informational, and appraisal) to this population so that certain conditions are accommodated for this target group to enable them to live a life replete with affection and kindness in their homes and more effectively alleviate their concerns regarding old age. Providing them sources of information and emotional support can similarly affect the lives of the elderly and contribute to the promotion of happiness and life satisfaction among them.

\section{CONFLICT OF INTEREST}

No potential conflict of interest relevant to this article was reported.

\section{ACKNOWLEDGMENTS}

We would like to thank the Deputy of Research and Technology (Hamadan University of Medical Sciences) for the financial support of this study.

This study is a part of the MSc thesis in health education \& promotion and supported originally by grants from the Hamadan University of Medical Sciences (project no., 950117107). 


\section{REFERENCES}

1. Diener E, Oishi S, Lucas RE. Personality, culture, and subjective wellbeing: emotional and cognitive evaluations of life. Annu Rev Psychol 2003;54:403-25.

2. Cohen S, Herbert TB. Health psychology: psychological factors and physical disease from the perspective of human psychoneuroimmunology. Annu Rev Psychol 1996;47:113-42.

3. Ross CE, van Willigen M. Education and the subjective quality of life. J Health Soc Behav 1997;38:275-97.

4. Helliwell JF, Huang H, Wang S. Social foundations of World happiness. In: Helliwell J, Layard R, Sachs J, editors. World happiness report 2017. New York (NY): Sustainable Development Solutions Network; 2017. p. 8-47.

5. Ghasemi A, Abedi A, Baghban I. The impact of group education based on Snyder's hop theory on the rate of happiness in eldery's life. Knowl Res Appl Psychol 2009;11:17-38.

6. Rastegarpour S. Survey the planning and management of elderly health services Tehran city. Chalus: Noushaher \& Chalus Azad University; 1997.

7. Hogstel MO, Kazer MW, Zembruzski C. Gerontology: nursing care of the older adult. Albany: Delmar Thompson Learning; 2001.

8. Seeman TE, Adler N. Older Americans: who will they be? Phi Kappa Phi Forum 1998;78:22.

9. Helgeson VS. Social support and quality of life. Qual Life Res 2003;12 Suppl 1:25-31.

10. Rathus SA. Psychology. 4th ed. Fort Worth (TX): Holt, Rinehart, and Winston; 1990.

11. Janevic MR, Janz NK, Dodge JA, Wang Y, Lin X, Clark NM. Longitudinal effects of social support on the health and functioning of older women with heart disease. Int J Aging Hum Dev 2004;59:153-75.

12. Salarvand SH, Abedi H. The elders' experiences of social support in nursing home: a qualitative study. Iran J Nurs 2007;20:39-50.

13. Gray RS, Rukumnuaykit P, Kittisuksathit S, Thongthai V. Inner happiness among Thai elderly. J Cross Cult Gerontol 2008;23:211-24.
14. Hamid N, Vatankhah M, Mehrabizadeh-Honarmad M. The efficacy of quality of life group training on happiness and vitality of aged men. J Urmia Univ Med Sci 2013;24:800-11.

15. Norbeck JS, Lindsey AM, Carrieri VL. Further development of the Norbeck Social Support Questionnaire: normative data and validity testing. Nurs Res 1983;32:4-9.

16. Motamedi Shalamzari A, Ezhei J, Azad Falah P, Kiyamanesh A. The impact social support in life satisfaction, general health and isolation feeling in older adults above 60 ages. J Psychol 2008;6:115-33.

17. Keykhosravi Beygzadeh Z, Rezaei A, Khalouei Y. The relationship between social support and life satisfaction with happiness among home-dwelling older adults in Shiraz. Iran J Ageing 2015;10:172-9.

18. Rashedi V, Gharib M, Rezaei M, Yazdani AA. Social support and anxiety in the elderly of Hamedan, Iran. Arch Rehabil 2013;14:110-5.

19. Berkman LF. The role of social relations in health promotion. Psychosom Med 1995;57:245-54.

20. Bozo O, Toksabay NE, Kurum O. Activities of daily living, depression, and social support among elderly Turkish people. J Psychol 2009;143:193-205.

21. Heiydari S, Salahshorian A, Rafie F, Hoseini F. Correlation of perceived social support and size of social network with quality of life dimension in cancer patients. Feyz J Kashan Univ Med Sci 2008;12:15-22.

22. Soltani T, Mazloomy MS, Morowati SM, Fallahzadeh H, Jafari A. Social support and its relation with daily activities among elderly people of Yazd. J Commun Health Res 2015;3:270-7.

23. Lu L. Social support, reciprocity, and weil-being. J Soc Psychol 1997;137:618-28.

24. Stephens MA, Bernstein MD. Social support and well-being among residents of planned housing. Gerontologist 1984;24:144-8.

25. Garousi S, Safizadeh H, Samadian F. The study of relationship between social support and quality of life among elderly people in Kerman. Jundishapur Sci Med J 2012;11:303-15.

26. VonDras DD, Madey SF. The attainment of important health goals throughout adulthood: an integration of the theory of planned behavior and aspects of social support. Int J Aging Hum Dev 2004;59:205-34. 